\title{
Comparison of the factors of the built environment influencing the decision to walk for short trips in two Spanish cities: Valencia and Granada
}

\author{
Sheila Ferrer* \\ Ph.D. Candidate, Transport Department, School of Civil Engineering, Universitat Politècnica de \\ València, Camino de Vera s/n, 46022 Valencia, Spain \\ E-Mail: $\underline{\text { shferlo@upv.es }}$
}

\section{Tomás Ruiz}

Associate Professor, Transport Department, School of Civil Engineering, Universitat Politècnica de València, Camino de Vera s/n, 46022 Valencia, Spain Tel: (+34) 963877370; Fax: (+34) 963877370; E-Mail: truizsa@tra.upv.es

* Corresponding author

\begin{abstract}
In this study, we use a qualitative methodology to identify and compare factors of the built environment influencing the decision to walk for short trips in two different Spanish cities: Valencia and Granada. Three focus groups were held in Valencia and two in Granada with participants who undertook, at least once a week, one short non-shopping trip in any travel mode (were "short trip" is defined as less than 30-45 minutes walking distance). A thematic analysis of the data using the software QSR NVivo was performed after the transcription of the video recordings. Results show that participants perceive more facilitators to walking in Granada than in Valencia, explained by the smaller size of the former city and the driving restriction policy in the city centre of Granada for private cars. The main common barriers to walking in the two cities were: insecurity from crime (absence of people, a poor street lighting or walking along a conflictive are), a high density of traffic lights and walking along large avenues. In the city of Valencia, crossing multilane avenues and large-diameter roundabouts are deterrents to walking. In Granada, very steep streets motivate the use of alternative travel modes.
\end{abstract}

Keywords: built environment, focus group, walking, pedestrian, short trip, mode choice 


\section{INTRODUCTION}

Promoting sustainable travel behavior is among the objectives of the European Union to reduce $\mathrm{CO}_{2}$ emissions from transportation (EC, 2011). Walking has attracted increasing attention in urban mobility studies in the last decades as one of the alternatives to motorized transportation. Some studies indicate that modal shift from car use to walking for short trips would reduce fuel consumption (Higgins, 2005) and $\mathrm{CO}_{2}$ emissions (Davis et al., 2007). Additionally, active transportation is also related to health, increasing physical activity and the prevention of chronic diseases (Woodcock et al., 2009).

Many studies have provided evidence of the association between neighborhood design and active transportation. Some reviews identify how researchers in transportation and urban planning (Hodgson et al., 2004; Hof, 2010; Saelens et al., 2003; Saelens \& Handy, 2008) and in population health (Owen at al., 2004) are examining potential environmental determinants of transport-related walking.

Many of the initial studies from the transportation field found that land use factors have a pervasive influence on mobility. For example, Cervero \& Kockelman (1997) found that density, land-use diversity and pedestrian-oriented designs reduce automobile trip rates and encourage non-auto travel modes. Greenwald \& Boarnet (2001) results suggest that regardless of the effects that land use has on individual non-work walking trips, the impacts take place at the neighborhood level. Rodriguez \& Joo (2004) found that the presence of sloping terrain decreases the attractiveness of walking and cycling. In addition to meso-scale (or neighborhood scale) built environmental factors such as residential density, land use mix or street connectivity, special attention should be given to microscale (or street level) built environment characteristics, such as the presence of trees, the width of the sidewalks, and the quality of the streets, as the roles of micro-scale elements are not well understood due to limited data availability (Lee et al., 2013; Kim et al., 2014). The current study examines macro and micro factors of the built environment determining the decision to walk for transportation.

\subsection{Definitions: walking for transportation and the built environment}

We are only interested in built environmental factors influencing walking to reach a destination, also defined as walking for transportation. In our study, trips related to recreational purposes (e.g., go to the gym, to the swimming pool, etc.) except strolling are considered walking for transportation as well.

Davison \& Lawson (2006) defined the built or physical environment as objective and perceived characteristics of the physical context in which people spend their time (e.g., home, neighborhood, school) including aspects of urban design (e.g., presence and structure of sidewalks), traffic density and speed, distance to and design of venues for 
physical activity (e.g., playgrounds, parks and school yards), crime, safety and weather conditions.

\subsection{Quantitative and qualitative approaches}

The relationship between walking among adults and the built environment has been observed by means of quantitative and qualitative approaches.

Quantitative methodologies use objective and perceived measures of the factors of interest to examine the link with walking for transportation. Objective measures of the built environment have been studied to explain their influence on physical activity and nonmotorized travel (Cervero \& Kockelman, 1997; Badland \& Schofield, 2005; Handy \& Clifton, 2001; Rodriguez \& Joo, 2004). Some studies use objective measures of the built environment characteristics at a micro-level or larger scale around individuals' residence (Cao et al, 2009; Clark et al., 2014; Greenwald \& Boarnet, 2001; Frank et al., 2007; Lovasi et al., 2013; Saelens \& Handy, 2008; Shriver, 1997; Van Dyck, 2010). Findings by Shriver (1997) suggest that walking-activity patterns are influenced by street connectivity, mixed use areas, and outdoor seating. Cao et al. (2009) show that mixed land uses, the availability of walking infrastructures, aesthetics quality and social context are associated with walking for transportation.

Other studies examine the relationship between walking and perceptions of attributes of the local neighborhood (Craig et al., 2002; Panter et al., 2014). Craig et al. (2002) modeled the relationship between walking to work and an environment score based on 18 neighborhood characteristics, and found that with the exception of visual interest and aesthetics, each neighborhood characteristic was correlated with walking (e.g., safety from crime, traffic, etc.). Panter et al. (2014) found that the proportion of car trips increased for commuters who reported that the route became less pleasant to walk or more dangerous to cross the road.

Some studies have focused on the understanding of factors influencing the walkability of the pedestrian environment (Ewing \& Handy, 2009; Kelly et al., 2011; Leslie et al., 2005; Van Dyck et al., 2010). Kelly et al. (2011) found that pedestrians consider important both traffic volume and the priority of vehicles to pedestrians. In addition, they also identified some of the factors improving pedestrian quality, such as clean pavements, connectivity and a perception of safety.

Different qualitative methodologies have been used to study how built environmental factors are related to walking for transportation. . For example, Van Cauwenberg et al. (2012) used walk-along interviews with 57 adults (over 65) to find out the perceived environmental factor influencing walking for transportation. Some studies used focus groups to research on neighborhood factors and active aging (Grant et al., 2010; Michael et al., 2006; Nathan et al., 2013). Other studies using focus groups are linked to children 
(Loitz \& Spencer-Cavaliere, 2013), or young people and older adolescents (Lake \& Townshend, 2013; Simons et al., 2013).

In a qualitative exploratory study, Locket el al. (2005) used focus-groups and a photovoice technique to examine environmental barriers and facilitators related to walking in 13 seniors citizens in Ottawa (Canada). Photo-voice is a technique in which photographs taken by community members are used to facilitate discussion between community members (Lockett et al., 2005; Wang \& Burris, 1997). Similarly, Gallagher et al. (2005) used focus-groups and a photo-voice methodology to identify the most important factors of the neighborhood environment that encourage or discourage walking in older, urban African Americans.

Recently, Ferrer et al. (2015) used focus groups in the city of Valencia (Spain) to identify built environmental factors influencing short walking distances for transportation among adults, with special attention to micro-scale attributes. This paper broadens previous research by Ferrer et al. (2015) with the aim to compare built environmental factors influencing walking short distances for transportation in two cities in Spain: Valencia and Granada. We use a qualitative approach based on focus groups. Section 2 describes the qualitative methodology; Section 3 describes the main results and Section 4 presents the conclusions of the study.

\section{METHODOLOGY}

\subsection{The areas of study: Valencia y Granada}

The two cities present very different characteristics. Valencia is the third largest city in Spain with 0.79 million inhabitants and a population in the metropolitan area of 1.8 million. In the case of Granada, the city has a population of 0.24 million and 0.49 million within its metropolitan area. The previous data is referred to 2014.

In terms of mobility within the cities (trips with origin and destination in the city), the modal split is shown in Table 1:

Table 1 - Modal split of internal mobility in the cities.

\begin{tabular}{|c|c|c|c|c|}
\hline City & Walking $(\%)$ & Car $(\%)$ & Transit $(\%)$ & Other $(\%)$ \\
\hline Valencia & 48 & 24 & 23 & 5 \\
\hline Granada & 54 & 19 & 20 & 7 \\
\hline
\end{tabular}

Source: Sustainable Urban Mobility Plan of Granada (2012) and Valencia (2013)

According to the Sustainable Urban Mobility Plan for Granada (2012), around 80\% of walking trips are shorter than 20 minutes and almost $50 \%$ are beyond 10 minutes. 
The City of Granada experimented dramatically changes in its transport system during the 1980s. Traffic is restricted in the city centre except for residents and public transport. The areas of the city with car use restrictions are shown in Figure 1.
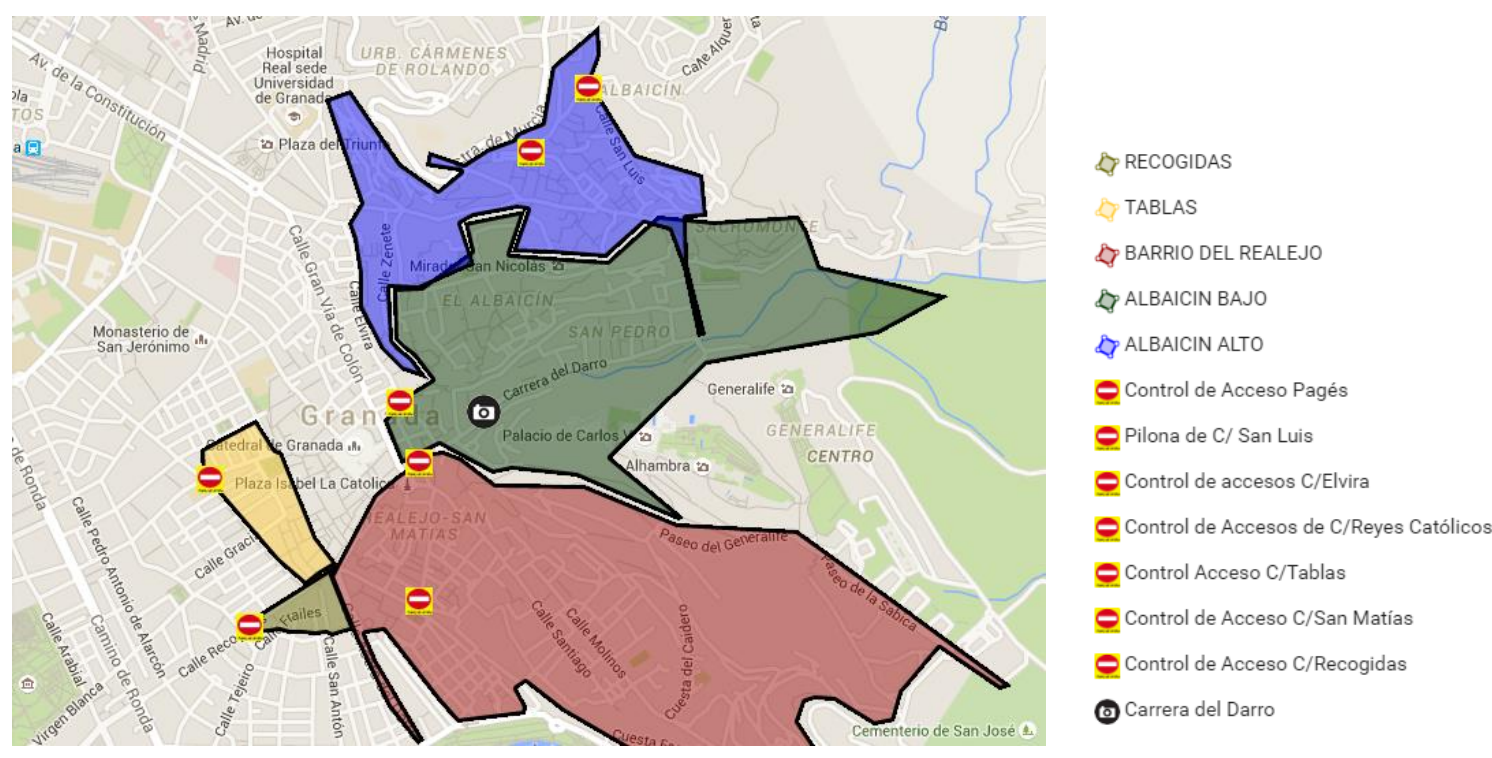

Figure 1- Map of the traffic restrictions in the city of Granada. Source: Google Maps (accessed on $31^{\text {st }}$ May 2016).

In terms of the public transport services, Granada has regular operation of transit buses and Valencia has also metro and tram.

\subsection{Recruitment}

The recruitment process of participants was carried out similarly in Valencia and Granada. Potential focus groups' participants were friends and relatives of Civil Engineering students and employees at Universitat Politècnica de València and Universidad de Granada. To be eligible to participate in the main focus groups, participants had to be over 30, make at least one short non-shopping trip in any travel mode once a week (were "short trip" was defined as less than 30-45 minutes walking distance), have no health problem that limits walking, and be willing to participate in a video-taped focus group (Ferrer et al., 2015). As most participants in main focus groups were facilitated by a group of students of Civil Engineering, an age criteria was established to avoid the recruitment of very young participants only (i.e. friends of the students), which would introduce a significant bias in the results of the study.

Potential participants filled out a recruiting questionnaire including socio-demographic characteristics (age, gender, address), information on a short non-shopping trip undertaken at least once a week (location of the origin and destination of the trip, travel mode, activity at destination and whether respondent returns to the origin) and answered questions related to their appropriateness to participate in a focus group (how they behave in a group context and with people they have just met, etc.). Trips provided by participants were verified using "Google Maps" as a proxy to check if they were short trips. Based on the 
questionnaire results, most suitable participants were selected to participate in the focus groups. They were contacted by phone and asked about the most habitual travel modes used for urban trips.

Participants in the main focus groups were homogenous according to age. In addition, all groups consisted of car users, pedestrians, cyclists and public transport users for short trips. Independently of the mode of transportation chosen for the short trip provided, regular car users were about half of the participants of each focus group. To reduce familiarity between participants in the focus groups and ensure a greater anonymity, no more than two participants recruited by the same student were together in a focus group. Furthermore, none of the students participated in the focus groups.

\subsection{Focus groups}

The approach used in this study is based on focus groups. Three focus groups were held in Valencia in march of 2014, and two in Granada in april of 2014. The first of the three groups in Valencia was a pilot focus group with graduated civil engineers and people currently employed at the School of Civil Engineering of Universitat Politècnica de València aged 28-32 years.

As explained in Ferrer et al. (2015), a total of 23 people participated in Valencia: 17 were residents in the city of Valencia, and the rest were residents of different municipalities of the region of Valencia located 3 to 40 miles away from the city centre (Paterna, Burjasot, Moncada and Játiva). In the case of the 14 participants in Granada, 8 were residents of the city and 6 residents of municipalities of the metropolitan area, located 2.5 to 3 miles away from the city centre (Huétor Vega, Peligros and La Zubia).

The characteristics of focus groups are presented in Tables 2 and 3.

Table 2- Characteristics of the focus groups in Valencia

\begin{tabular}{|c|c|c|c|c|c|c|}
\hline Focus group & Description & $\begin{array}{l}\text { Number of } \\
\text { participants }\end{array}$ & $\begin{array}{c}\text { Range of } \\
\text { age* }\end{array}$ & Average & Male & Female \\
\hline $\begin{array}{l}\text { Pilot focus } \\
\text { group } \quad \text { (V0) }\end{array}$ & $\begin{array}{l}\text { Employees at the } \\
\text { School of Civil Eng. } \\
\text { Universitat Politècnica } \\
\text { de València (UPV) }\end{array}$ & 7 & $28-32$ & 30 & 4 & 3 \\
\hline $\begin{array}{c}\text { Focus group } 1 \\
\text { (V1) }\end{array}$ & $\begin{array}{l}\text { Relatives and friends } \\
\text { of students of Civil } \\
\text { Eng. at UPV }\end{array}$ & 9 & $40-60 *$ & $50 *$ & 4 & 5 \\
\hline $\begin{array}{c}\text { Focus group } 2 \\
\text { (V2) }\end{array}$ & $\begin{array}{l}\text { Relatives and friends } \\
\text { of students of Civil } \\
\text { Eng. at UPV }\end{array}$ & 7 & $40-60 *$ & $50 *$ & 1 & 7 \\
\hline
\end{tabular}

\footnotetext{
* For Focus Group 1 and 2, only the range of age of each participant was known.
} 
Table 3- Characteristics of the focus groups in Granada

\begin{tabular}{ccccccc}
\hline Focus group & Description & $\begin{array}{c}\text { Number of } \\
\text { participants }\end{array}$ & $\begin{array}{c}\text { Range } \\
\text { of age* }\end{array}$ & Average & Male & Female \\
\hline $\begin{array}{c}\text { Focus group 1 } \\
\text { (G1) }\end{array}$ & $\begin{array}{c}\text { Employees, relatives and } \\
\text { friends of students of Civil } \\
\text { Eng. at Universidad de } \\
\text { Granada (UG) }\end{array}$ & 7 & $25-65$ & 50 & 3 & 4 \\
\hline $\begin{array}{c}\text { Focus group 2 } \\
\text { (G2) }\end{array}$ & $\begin{array}{c}\text { Employees, relatives and } \\
\text { friends of students of Civil } \\
\text { Eng. at UG }\end{array}$ & 7 & $24-59$ & 32 & 4 & 3 \\
\hline
\end{tabular}

Focus groups were conducted in Spanish and lasted around 90 minutes, which is the average duration for a focus group (Morgan, 1996). The number of participants in each focus group varied from 7-9, following Krueger \& Casey (2000) recommendations. The first author was the moderator of four of the focus groups and was aided by a research assistant, as suggested by Asbury (1995). Participants, moderator and research assistant were seated in a circle without a table in the middle to facilitate the discussion.

The moderator followed a semi-structured discussion guide developed for the study in consultation with the research team and followed recommendations for focus groups methodology (Krueger \& Morgan, 1994; Morgan, 1996). In order to ensure everyone to participate equally in the discussion, the research assistant helped the moderator in the task of identifying less participative individuals, and the moderator solicited answers from those individuals. The first author observed that no new concepts were discussed during the third focus group, thus data saturation was reached (Ferrer et al., 2015).

Table 4 presents a summary of the discussion guide. 
Table 4- Discussion guide

\begin{tabular}{|c|c|c|c|}
\hline $\begin{array}{c}\text { Question } \\
\text { type }\end{array}$ & Objective & Question & $\begin{array}{c}\text { Timing } \\
(\min )\end{array}$ \\
\hline Opening & \multicolumn{2}{|c|}{ Welcome participants, objective of the focus group and set ground rules. } & 5 \\
\hline \multirow{4}{*}{ Introduction } & Icebreaker activity & 1. Tell us your name and your favorite travel mode & 5 \\
\hline & Start discussion & $\begin{array}{l}\text { 2. How have your habits changed as a consequence of the } \\
\text { financial crisis?* }\end{array}$ & 5 \\
\hline & $\begin{array}{l}\text { Distance willing to } \\
\text { walk }\end{array}$ & $\begin{array}{l}\text { 3. How far are you willing to walk to go to a place before } \\
\text { considering a different travel mode? Think in minutes } \\
\text { walking (short trip definition) }\end{array}$ & 5 \\
\hline & $\begin{array}{l}\text { Common factors } \\
\text { influencing travel } \\
\text { mode choice for } \\
\text { short trips }\end{array}$ & $\begin{array}{l}\text { 4. What things influence the travel mode choice for short } \\
\text { trips without carrying heavy goods? }\end{array}$ & 5 \\
\hline \multirow{5}{*}{ Key topic } & $\begin{array}{l}\text { Built environmental } \\
\text { factors influencing } \\
\text { the travel mode } \\
\text { choice for short } \\
\text { trips }\end{array}$ & $\begin{array}{l}\text { 5. Imagine you have to go to a place from home and later } \\
\text { you come back. You are not carrying heavy goods and the } \\
\text { weather is fine. Which factors of the built environment } \\
\text { influence your decision to walk? }\end{array}$ & 5 \\
\hline & $\begin{array}{l}\text { Factors influencing } \\
\text { the walking } \\
\text { experience }\end{array}$ & $\begin{array}{l}\text { 6. Imagine you have to walk for transportation for short } \\
\text { trip, the weather is fine and you are not carrying heavy } \\
\text { goods. What things of the walking route would make it } \\
\text { walking more attractive? } \\
\text { 7. What things of the walking route would make it } \\
\text { walking unattractive? } \\
\text { 8. Pictures of streets of Valencia are shown. Imagine you } \\
\text { are walking for transportation along that street, which } \\
\text { things you see are attractive? Which things make the walk } \\
\text { unattractive? }\end{array}$ & 35 \\
\hline & $\begin{array}{l}\text { Factors related to } \\
\text { safety from traffic }\end{array}$ & $\begin{array}{l}\text { 9. While walking, in which moments do you feel you } \\
\text { could experience an accident and which risks do you find? }\end{array}$ & 5 \\
\hline & $\begin{array}{l}\text { Barriers to walking } \\
\text { and secondary } \\
\text { factors }\end{array}$ & $\begin{array}{l}\text { 10. Which things in the environment that you see, hear, } \\
\text { smell or experience during a walking route, can influence } \\
\text { your travel mode choice? } \\
\text { 11. Do any of those factors influence the walking route } \\
\text { you choose? }\end{array}$ & 5 \\
\hline & $\begin{array}{l}\text { Influence of the } \\
\text { purpose of the trip }\end{array}$ & $\begin{array}{l}\text { 12. Does the built environment influence similarly the } \\
\text { travel mode you choose for trips to work or other types of } \\
\text { trips? }\end{array}$ & 5 \\
\hline \multirow[t]{2}{*}{ Ending } & $\begin{array}{l}\text { Identify any } \\
\text { additional factor not } \\
\text { discussed }\end{array}$ & $\begin{array}{l}\text { 13. Anything else influencing the travel mode you choose } \\
\text { for short trips that we should have talked about? }\end{array}$ & 5 \\
\hline & Ending & Thank respondents, satisfaction questionnaire and gifts. & 5 \\
\hline
\end{tabular}

*Only asked in Valencia focus groups 


\subsection{Data analysis}

The data analysis carried out consisted in the same steps followed in Ferrer et al. (2015). A thematic analysis of the data collected was conducted. This interpretative methodology allowed us to identify and analyze reporting patterns (themes) within the data. Tasks developed included transcription of all video recordings; paraphrasing; coding; and data interpretation based on quantitative counts.

\section{RESULTS}

Qualitative data analysis of answers to questions 5-13 revealed five main categories of built environmental factors influencing walking for transportation (Ferrer et al., 2015): safety from crime (street lighting, other people, cleanliness, etc.), traffic safety (traffic volume, traffic speed, crossing waiting times, etc.), walking facilities (sidewalk width, obstacles, etc.), aesthetics (presence of green elements, buildings, noise, etc.), convenience and other perceptions (availability of car parking, hills and pedestrian volume, open and wide spaces and length perception).

Built environmental factors identified could be classified as:

- Barrier/deterrent or facilitator to walking for transportation: factor that by itself explicitly influences the decision to walk for at least one person in the focus groups

- Secondary factor influencing walking: factor that is not mentioned as a barrier or facilitator to walking, but is related to the pleasantness or comfort of the walking experience and/or explicitly influences the walking route choice

In this study we only focus on barriers and facilitators to walking. Findings are supported by comments made during the focus groups, conveniently identified in the following way: participant gender, participant's most habitual travel modes for urban trips in general (habitual car user, pedestrian and public transportation user, etc.), age, participant reference, and focus group number (V0 to V2 and G1 to G2, as identified in Tables 2 and $3)$.

Qualitative data interpretation is reinforced by quantitative counts of the participants discussing certain factors, following Krueger's criteria (1994) of including frequency and extensiveness of comments. This criterion was also previously used by Cauwenberg et al. (2012) and Simons et al. (2013). Thus, when a factor was discussed by less than $25 \%$, we defined it "few", for between $25 \%$ and $50 \%$, we defined it "some", for between $50 \%$ and $75 \%$, we defined it "a lot of" and for more than $75 \%$ of the participants, we defined it "almost all" in the results' description. 


\subsection{Barriers}

The main barriers to walking for transportation are included in Table 5. Barriers could be mentioned in both cities (common barriers) or only in one of the cities (different barriers).

Table 5- Barriers to walking

\begin{tabular}{|c|c|c|}
\hline Barriers & Valencia & Granada \\
\hline Common barriers & \multicolumn{2}{|c|}{$\begin{array}{l}\text { - Fear of crime: absence of people }{ }^{* 1 * 2} \text {, poor lighting at } \\
\text { night } * 1 * 2 \text { o walking along a conflictive area } \\
\text { - Density of traffic lights } \\
\text { - Walking along large avenues } \\
\text { - Lack of sidewalks }\end{array}$} \\
\hline Different barriers & $\begin{array}{l}\text { - Crossing multi-lane } \\
\text { avenues or large-diameter } \\
\text { roundabouts } \\
\text { - Smell }\end{array}$ & $\begin{array}{l}\text { - } \\
\text { - } \quad \text { Lack of shade areas in } \\
\text { summer }\end{array}$ \\
\hline
\end{tabular}

*1 Reported by more than $50 \%$ of the participants in Valencia

*2 Reported by more than $50 \%$ of the participants in Granada

\subsubsection{Common barriers}

\section{Fear of crime}

The perception of fear of crime is the most important barrier to walking for short trips, particularly for women. In both cities, Valencia and Granada, all female participants revealed to avoid walking for transportation for some trips due to fear of crime, preferring the use of alternative travel modes. The absence of people, walking along an area perceived as conflictive or a poor lighting at night are the main reasons. Only a few men indicated to feel insecure under these circumstances and opt for a different travel mode.

\section{Density of traffic lights}

In the groups held in Granada, a young participant used to walk for transportation indicated that routes with many traffic lights influence his travel mode choice, even if the trip was along a pedestrian route:

- "If there is a pedestrian route but in the middle there are 250 traffic lights..." (man, pedestrian, 24, G2)

Similarly, in Valencia a high intersection density may discourage a few people to walk. For example, a female indicated:

- "If you are walking but every 50-100 meters you have to stop because there is a crossing... damn!" (woman, car user and pedestrian, 50-60, V2). 
She also stated that this was a reason for driving the car for some short trips.

\section{Walking along large avenues}

In one of the groups of Valencia, a habitual female car user referred to the importance of the walking route to a destination:

- "If it is along large avenues with many cars that would not encourage me to walk" (woman, car user, 30-40, V0).

Similarly, two habitual female car users stated that they prefer to take the car for trips along avenues in Valencia.

In the case of Granada, long avenues are perceived as monotonous and deter people from walking for short trips. In the second of the focus groups, one of the participants spontaneously said:

- "For example, I'm thinking in going to the bus station...it's not a dangerous neighborhood but all those avenues make the journey seem longer" (man, car user and pedestrian, 27, G2)

The previous comment started an interesting conversation:

- "It makes the journey more boring" (woman, pedestrian and car user, 59, G2)

- "Yes" (man, pedestrian, 30, G2).

- "But it is also because they are lively" (man, pedestrian, 24, G2)

- "No, it is because those streets are very wide, very long... seems you will never reach your destination (man, car user and pedestrian, 27, G2)

- "But as there are no retails, there is no live"(man, pedestrian, 24, G2)

- "Sure, there aren't" (man, car user and pedestrian, 27, G2)

- "It is more deserted" (man, pedestrian, 24, G2)

- "There are only buildings, buildings and buildings" (man, pedestrian, 30, G2)

- "I think it is because of the street width..walking half an hour along a very wide and very long street...It is more tiring, even only psychologically" (man, car user and pedestrian, 27, G2)

- "But I think it is because of the monotony" (man, pedestrian, 24, G2)

- "Yeah, seems you don't go forward" (woman, pedestrian and public transportation user, 25, G2)

- "If you walk down Gran Via, even it is a straight street, you can see shops, restaurants, a church, a woman selling something, it is different. However, if you walk near the bus station, streets are straight, there is nothing, there are no shops, only buildings, that's all. It's boring" (man, pedestrian, 24, G2). 


\section{Poor/lack of sidewalks}

One female car user in Valencia said that sidewalk conditions influence her to walk or not:

- "For example, if the sidewalks are not wide enough and comfortable to walk, I would stop walking [...] For comfort and for safety, because some streets are so narrow [...]". (woman, car user and pedestrian, 20-30, V0).

Apart from safety from crime, one male used to walking for transportation identifies the lack of sidewalks as the most important deterrent to walking: "I just need a sidewalk, of 1.5 meters or similar" (man, pedestrian and public transportation user, 40-50, V2).

A few participants in Granada also referred to the lack of sidewalks as a barrier to walking.

\subsubsection{Different barriers}

\section{Crossing multi-lane avenues or large-diameter roundabouts (Valencia)}

In Valencia, a few participants referred to the inconvenience of a high density of pedestrian traffic lights along a walking trip, especially when crossing large avenues and roundabouts. For example, a female participant referred to a 10 minutes walking route between two shopping malls (figure 2):

- "If you have to go from Aqua Mall to El Saler Mall, you have to cross a roundabout and all the avenues...it's terrible. Sometimes, [...] I say (to her husband)...no! forget about it, we will take the car" (woman, pedestrian and car user, 40-50, V2).

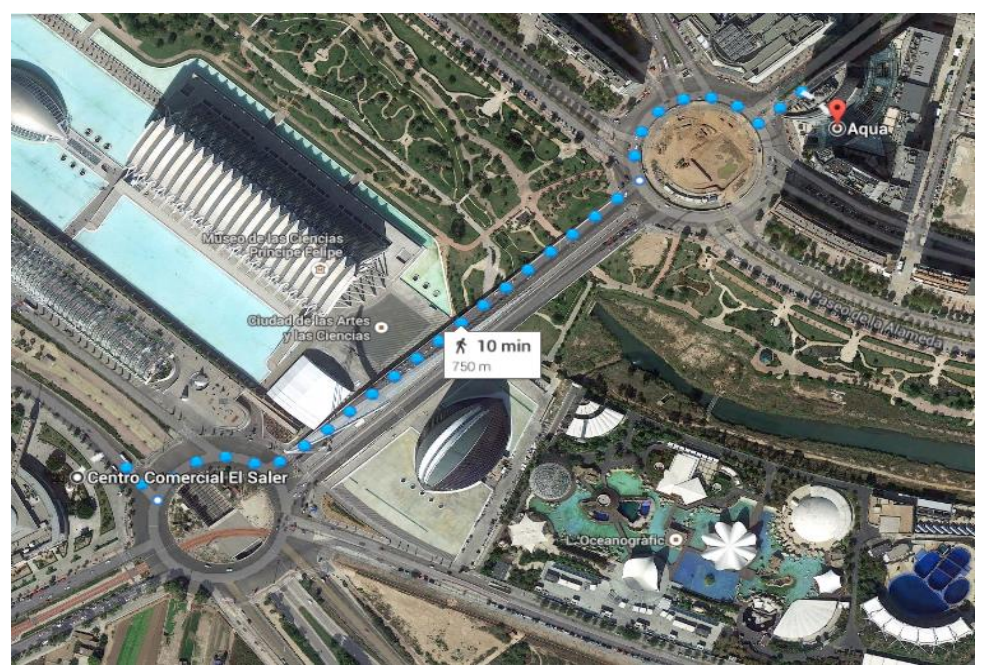

Figure 2- Aerial view of the walking route between two malls in the city of Valencia. Google Maps estimates it is a 10 min walk ( $750 \mathrm{~m}$ long). Source: Google Street View (accessed on $20^{\text {th }}$ October 2014). 


\section{Smell (Valencia)}

One participant in the pilot focus group in Valencia said:

- "If it smells very, very badly, I don't like it...if it's ugly it does not influence me much, the same if there is much noise, but with smell during 10 minutes, I can't stand it" (woman, pedestrian and public transport user, 20-30, V0).

\section{Steep streets (Granada)}

In the city of Granada, very steep streets were identified as deterrents to walking by some participants. For example:

- "If I know I have to walk up a steep street and it is going to be hard for me, I take the bus" (woman, pedestrian and car user, 59, G2).

In the case of Valencia, two participants remarked that the flat topography of the city encourages them to walk.

\section{Lack of shade areas in summer (Granada)}

A woman in Granada said:

- "If it's summer, the weather is unbearably hot and the walking route is in the sun with no shade, I don't go walking, I take the bus" (woman, pedestrian and car user, $59, \mathrm{G} 2)$.

In addition, when shown Figure 3, some participants in Granada mentioned positively the presence of sunshades in summer in the street.

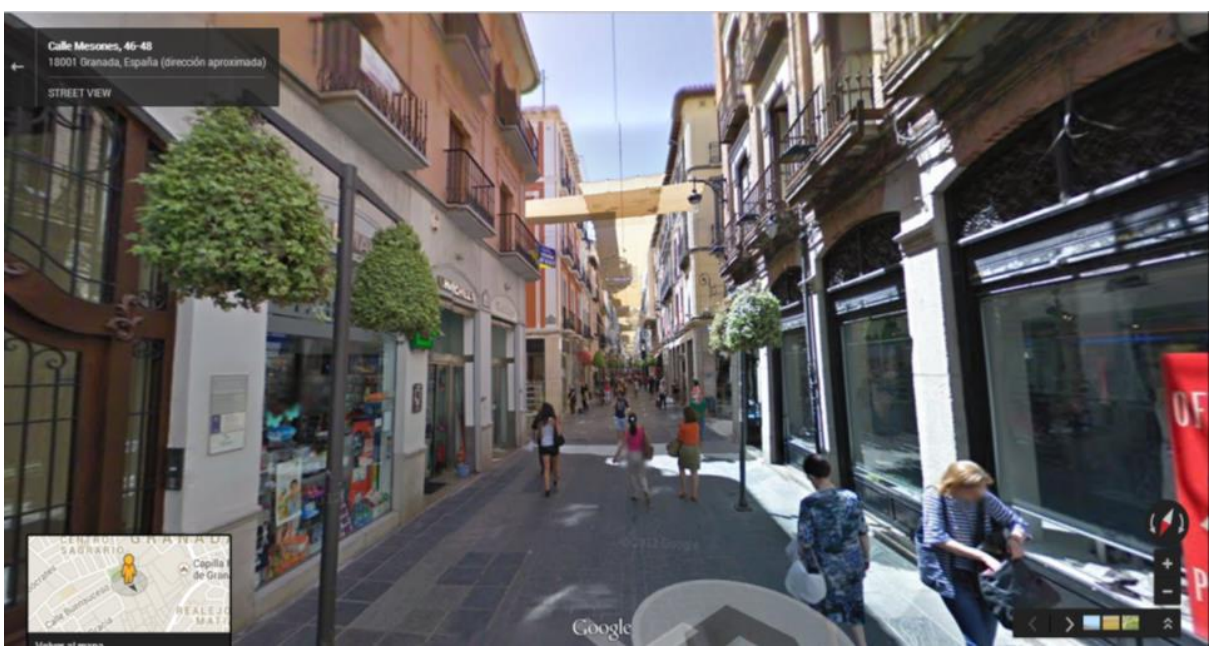

Figure 3- Photograph of a pedestrian street of Granada shown in the focus groups (G1 and G2).

Source: Google Street View (accessed on $8^{\text {th }}$ april 2014). 


\subsection{Facilitators}

Table 6 includes facilitators of walking for short trips identified in focus groups.

Table 6- Facilitators to walking

\begin{tabular}{|c|c|c|}
\hline $\begin{array}{l}\text { Facilitators to } \\
\text { walking }\end{array}$ & Valencia & Granada \\
\hline Common facilitators & \multicolumn{2}{|c|}{$\begin{array}{l}\text { - } \quad \text { Lack of car parking space at destination } * 1 * 2 \\
\text { - } \quad \text { The walking route is perceived as pleasant } * 2\end{array}$} \\
\hline Different facilitators & - & $\begin{array}{l}\text { - } \text { City with short distances } \\
\text { - } \\
\text { - } \\
\text { Hedestrian streets } \\
\text { (driving restriction zones in } \\
\text { the city centre and/or stress to } \\
\text { due traffic congestion) }\end{array}$ \\
\hline
\end{tabular}

*1 Reported by more than $50 \%$ of the participants in Valencia

*2 Reported by more than $50 \%$ of the participants in Granada

\subsubsection{Common facilitators}

\section{Lack of car parking space at destination}

In Valencia, most car users confirmed that the difficulty to park the car was very important to avoid car use for short trips:

- "The only thing that would make me walk to the University would be the lack of car parking [...]. And in a short trip to another place, if there is no car parking, despite bad weather, I prefer to walk." (woman, car user, 30-40, V0)

- "In my case, for a short trip, if I had car parking at destination, I would drive" (woman, car user, 40-50, V1).

Another male participant confirmed that the presence of parking when he visits the doctor would encourage him to drive:

- "Despite the fact that the doctor is within walking distance, I would still use the car as long as I can park" (man, car user and pedestrian, 50-60, V1)

Similarly, a lot of participants in the focus groups of Granada added that the lack of car parking and the difficulty to park were important, and some of them also mentioned the difficulty to drive. Asking them about the use of the car for short trips in the city, they answered: 
- "Your own car? to take it in Granada? You have to be really brave! It is better to keep it in the garage and use it for long distances" (man, pedestrian and public transportation user, 25, G1)

- "It is high-risk" (man, pedestrian, 63, G1)

- 'For example, if you want to go to el Corte Inglés, you don't even consider to take the car because you are not going to be able to park, so you decide to go walking" (man, pedestrian, 30, G2)

- "For me the lack of car parking is the main reason for not using the car, otherwise I would take it" (man, car user and pedestrian, 27, G2)

\section{The walking route is perceived as pleasant}

One participant in Valencia and some in Granada referred to the perception of a pleasant walking trip to the destination as an important factor in their decision to walk.

In the pilot focus group in Valencia, a female participant said:

- "For me is important the walking route, if it is pleasant, I feel like walking" (woman, car user, 30-40, V0).

Also a participant in Granada:

- "It also influences me that the route is pleasant...The existence of distractions, a comfortable walk, a comfortable pavement" (woman, pedestrian and public transportation user, 26, G2).

And a woman replied suggesting that walking in the city centre of Granada meets all the previous conditions:

- "It depends on all what she said...and also if there are no people in the streets or you are walking alone, obviously you take the car, but if it is a walk through the city centre, I always walk" (woman, pedestrian and public transportation user, 59, $\mathrm{G} 2)$.

A habitual car user added:

- "I am used to take the car to go everywhere, but I acknowledge that sometimes I leave the car at home because I think -From here to there the walk is pleasant-" (man, car user and pedestrian, 27, G2)

A participant used to walk for transportation answered:

- "I sum it all up in the street life...I mean: you see colors, a shop, a bar...it's a set" (man, pedestrian, 24, G2) 
Also, when shown Figure 3, a few respondents in the second of the focus groups in Granada referred to the pedestrian street as very pleasant to walk.

\subsubsection{Different facilitators}

\section{Hard to drive in the city (Granada)}

Some participants indicated it was hard to drive in Granada when asked about the possibility to use the car for short trips:

- "First, traffic is restricted in the city centre [...] so you can't drive, and second, the blue zone is on the outskirts of the city, there is no blue zone in the centre, so you can't park" (man, pedestrian and public transportation user, 61, G1)

- "Currently, many of the streets of the city centre are pedestrian, so you can't drive there, you would have to park on the outskirts and then walk to the places you want to go [...]" (woman, pedestrian and public transportation user, 59, G1)

Other comments were related to the stress of driving in the city:

- "There is a lot of stress while driving in Granada" (man, pedestrian, 63, G1)

- "Here you get stressed even if you just drive 15 minutes. First, due to the traffic congestion [...]" (man, pedestrian and public transportation user, 25, G1)

\section{City with short distances (Granada)}

In the first group in Granada, all participants except one of them indicated that for a 15 minutes walking trip they only considered walking:

- "I think in Granada everyone [...] Granada is small, from every neighborhood to the city centre you only have a 30 minutes walk" (man, pedestrian and public transportation user, 61, G1)

- "Yeah, in Granada everyone (walks)[...]" (woman, pedestrian and public transportation user, 59, G1)

- "Distances are very short in Granada" (man, pedestrian, 63, G1)

More participants added:

- "It is for convenience and also because the city is small and you can go from one end to the other" (woman, pedestrian and public transportation user, 48, G1)

- "Granada is a comfortable city... you can go shopping to the city centre, you also have all the public institutions, hospitals, (all) in the city centre [...]" (woman, pedestrian and public transportation user, 59, G1)

Two women agreed with the last comment. 


\section{Pedestrian streets (Granada)}

In Granada, two participants used to walk said that pedestrian routes encourage them to walk, for example, one of them said:

- "For me, one of the most important things is the street to be pedestrian [...] for example, if the route to a place is almost all pedestrian I prefer to walk rather than using an alternative travel mode" (woman, pedestrian and public transportation user, 26, G2).

\section{CONCLUSIONS}

This study used focus groups to compare factors of the built environment influencing walking for transportation in adults in two Spanish cities: Valencia and Granada. Results show that participants perceive more facilitators to walking in Granada than in Valencia, explained by the smaller size of the former city and the driving restriction policy in the city centre of Granada for private cars. Common facilitators to walking are the lack of car parking spaces at destination of the trip and a perception of a pleasant walking route. In the particular case of the city of Granada, the fact that blue zones for parking are on the outskirts also encourages walking for short trips in the city centre. The main barriers for short walking trips identified in both cities are: fear of crime (absence of people, a poor street lighting at night or a conflictive area), a high density of traffic lights and walking along large avenues. Among the barriers, safety from crime seems to be the most important deterrent to walking. However, there are differences in the perceptions of safety according to gender: for all female the feeling of insecurity constitutes a barrier to walking, and only for some male it is a deterrent. In addition, multi-lane avenues and large-diameter roundabouts are mentioned as possible deterrents to walking in the city of Valencia, due to the high density of pedestrian traffic signals with a poor coordination, leading to long crossing waiting times. In Granada, short trips with very steep streets or walking routes with no shade in summer are barriers to walking.

Several transport policy lessons can be derived from our results. In general, smaller cities are more walkable because distance between different activity locations is shorter than in bigger cities. Therefore, big cities need to provide more opportunities to carry out different activities without leaving the neighborhood to promote walking.

It is also important to clearly define walking itineraries and walking zones in big cities. Parking spaces and areas where driving is freely allowed should be clearly separated from the former. Where both cars and pedestrians have to share the urban space, policies toward walking preference should be implemented. Additionally, following the example of Granada, conveniently designed traffic and parking restrictions in the city of Valencia could encourage more walking for transportation. 
In Valencia and Granada, a lot of participants considered unpleasant walking down caroriented avenues, with many lanes and noise from traffic. However, some avenues were seen as more walkable and pleasant. For example, many participants in both cities agreed that walking down wide avenues divided by a green pedestrian boulevard was more pleasant. Thus, existing multi-lane avenues could be redesigned to be more pedestrianfriendly, and urban planners should also consider these preferences when designing new avenues.

Finally, to confirm the findings of this qualitative study, an online survey will be designed using a quantitative approach.

\section{ANKOWLEDGEMENTS}

We would like to thank the Spanish Ministry of Science and Innovation for funding the research project PEATON-TRA2011-27415. Furthermore, we would also like to thank the participants in the study, Pablo García-Garcés for his assistance with the focus groups, Rocío de Oña and José Luis Machado for their help to organize the focus groups in Granada, and Lidón Mars for her help in conducting focus groups.

\section{REFERENCES}

Asbury, J. E. (1995). Overview of focus group research. Qualitative health research, 5(4), 414-420.

Badland, H. M., \& Schofield, G. M. (2005). The built environment and transport-related physical activity: what we do and do not know. Journal of Physical Activity \& Health, 2(4).

Cao, X. J., Mokhtarian, P. L., \& Handy, S. L. (2009). The relationship between the built environment and nonwork travel: A case study of Northern California.Transportation Research Part A: Policy and Practice, 43(5), 548-559. http://dx.doi.org/10.1016/j.tra.2009.02.001.

Cervero, R., \& Kockelman, K. (1997). Travel demand and the 3Ds: density, diversity, and design. Transportation Research Part D: Transport and Environment, 2(3), 199-219.

Craig, C. L., Brownson, R. C., Cragg, S. E., \& Dunn, A. L. (2002). Exploring the effect of the environment on physical activity: a study examining walking to work. American journal of preventive medicine, 23(2), 36-43. http://dx.doi.org/10.1016/S07493797(02)00472-5.

Davis, A., Valsecchi, C., \& Fergusson, M. (2007). Unfit for purpose: How car use fuels climate change and obesity.

Davison KK, Lawson CT. (2006). Do attributes in the physical environment influence children's physical activity? A review of the literature. International Journal of 
Behavioral Nutrition and Physical Activity, 3:19. http://dx.doi.org/10.1186/14795868-3-19.

European Commission - EC. White Paper. Roadmap to a Single European Transport Area- Towards a competitive and resource efficient transport system [COM(2011)144]. Publications Office of the European Union, Luxembourg (2011).

Ewing, R., \& Handy, S. (2009). Measuring the unmeasurable: Urban design qualities related to walkability. Journal of Urban Design, 14(1), 65-84. http://dx.doi.org/10.1080/13574800802451155

Ferrer, S., Ruiz, T., \& Mars, L. (2015). A qualitative study on the role of the built environment for short walking trips. Transportation research part $F$ : traffic psychology and behaviour, 33, 141-160.

Gallagher, N. A., Gretebeck, K. A., Robinson, J. C., Torres, E. R., Murphy, S. L., \& Martyn, K. K. (2010). Neighborhood factors relevant for walking in older, urban, African American adults. Journal of aging and physical activity, 18(1), 99-115

Grant, T. L., Edwards, N., Sveistrup, H., Andrew, C., \& Egan, M. (2010). Inequitable walking conditions among older people: examining the interrelationship of neighbourhood socio-economic status and urban form using a comparative case study. BMC public health, 10(1), 677.

Greenwald, M. J., \& Boarnet, M. G. (2001). Built environment as determinant of walking behavior: Analyzing nonwork pedestrian travel in Portland, Oregon.Transportation Research Record: Journal of the Transportation Research Board, 1780(1), 33-41.

Higgins, P. A. (2005). Exercise-based transportation reduces oil dependence, carbon emissions and obesity. Environmental Conservation, 32(03), 197-202.

Hodgson, F. C., Page, M., \& Tight, M. R. (2004). A review of factors which influence pedestrian use of the streets: Task 1 report for an EPSRC funded project on measuring pedestrian accessibility.

Hof, T. (2010). TNO Report: A literature review of individual, perceived physical and social environmental factors related to walking. TNO Defense, Security and Safety.

Kelly, C. E., Tight, M. R., Hodgson, F. C., \& Page, M. W. (2011). A comparison of three methods for assessing the walkability of the pedestrian environment. Journal of Transport Geography, 19(6), 1500-1508. $\quad$ http://dx.doi.org/10.1016/ j.jtrangeo.2010.08.001

Kim, S., Park, S., \& Lee, J. S. (2014). Meso-or micro-scale? Environmental factors influencing pedestrian satisfaction. Transportation Research Part D: Transport and Environment, 30, 10-20. http://dx.doi.org/10.1016/j.trd.2014.05.005.

Krueger RA, Morgan DL: Developing questions for focus groups: focus group kit 3. 1994, 3

Krueger RA \& Casey MA (2000) Focus Groups: A Practical Guide for Applied Research, 3rd ed. Thousand Oaks, CA: Sage Publications.

Lake, A. A., \& Townshend, T. G. (2013). Exploring the built environment, physical activity and related behaviours of young people attending school, college and those not in employment. Journal of public health,35(1), 57-66. doi: 10.1093/pubmed/fds059.

Lee, C., Zhu, X., Yoon, J., \& Varni, J. W. (2013). Beyond distance: Children's school travel mode choice. Annals of Behavioral Medicine, 45(1), 55-67. Doi: 10.1007/s12160-012-9432-z. 
Leslie, E., Saelens, B., Frank, L., Owen, N., Bauman, A., Coffee, N., \& Hugo, G. (2005). Residents' perceptions of walkability attributes in objectively different neighbourhoods: a pilot study. Health \& place, 11(3), 227-236.

Loitz, CC. and Spencer-Cavaliere, N. (2013). Exploring the barriers and facilitators to children's active transportation to and from school from the perspectives of practitioners. Journal of Physical Activity \& Health, 10(8):1128-35.

Lovasi, G. S., Schwartz-Soicher, O., Neckerman, K. M., Konty, K., Kerker, B., Quinn, J., \& Rundle, A. (2013). Aesthetic amenities and safety hazards associated with walking and bicycling for transportation in New York City.Annals of behavioral medicine, 45(1), 76-85. doi: 10.1007/s12160-012-9416-z.

Michael, Y. L., Green, M. K., \& Farquhar, S. A. (2006). Neighborhood design and active aging. Health \& place, 12(4), 734-740.

Morgan, D. L. (1996). Focus groups. Annual review of sociology, 129-152.

Nathan, A., Wood, L., \& Giles-Corti, B. (2013). Environmental Factors Associated With Active Living in Retirement Village Residents Findings From an Exploratory Qualitative Enquiry. Research on Aging, 35(4), 459-480. http://dx.doi.org/10.1177/0164027512454886.

Owen, N., Humpel, N., Leslie, E., Bauman, A., \& Sallis, J. F. (2004). Understanding environmental influences on walking: review and research agenda. American journal of preventive medicine, 27(1), 67-76.

Panter, J., Griffin, S., \& Ogilvie, D. (2014). Active commuting and perceptions of the route environment: A longitudinal analysis. Preventive medicine, 67, 134-140.

Rodríguez, D. A., \& Joo, J. (2004). The relationship between non-motorized mode choice and the local physical environment. Transportation Research Part D: Transport and Environment, 9(2), 151-173.

Saelens, B. E., Sallis, J. F., \& Frank, L. D. (2003). Environmental correlates of walking and cycling: findings from the transportation, urban design, and planning literatures. Annals of behavioral medicine, 25(2), 80-91

Saelens, B. E., \& Handy, S. L. (2008). Built environment correlates of walking: a review. Medicine and science in sports and exercise, 40(7 Suppl), S550-66.

Shriver, K. (1997). Influence of environmental design on pedestrian travel behavior in four Austin neighborhoods. Transportation Research Record: Journal of the Transportation Research Board, 1578(1), 64-75.

Simons, D., Clarys, P., De Bourdeaudhuij, I., de Geus, B., Vandelanotte, C., \& Deforche, B. (2013). Factors influencing mode of transport in older adolescents: a qualitative study. BMC public health, 13(1), 323. doi:10.1186/1471-2458-13-323.

Van Cauwenberg, J., Van Holle, V., Simons, D., Deridder, R., Clarys, P., Goubert, L., Nasar, J., Salmon, J., De Bourdeaudhuij,I., \& Deforche, B. (2012). Environmental factors influencing older adults' walking for transportation: a study using walk-along interviews. Int J Behav Nutr Phys Act, 9(1), 85. http://dx.doi.org/10.1186/1479-58689-85.

Van Dyck, D., Cardon, G., Deforche, B., Sallis, J. F., Owen, N., \& De Bourdeaudhuij, I. (2010). Neighborhood SES and walkability are related to physical activity behavior in Belgian adults. Preventive medicine, 50, S74-S79. doi: 10.1016/j.ypmed.2009.07.027.

Wang, C., \& Burris, M.A. (1997).Photovoice: Concept, methodology, and use for participatory needs. Health Education \& Behavior 1997; 24:369-387. doi: 10.1177/109019819702400309. 
Woodcock, J., Banister, D., Edwards, P., Prentice, A. M., \& Roberts, I. (2007). Energy and transport. The Lancet, 370(9592), 1078-1088 